\title{
Acute vulval edema leading to urinary retention in a lady with pre- eclampsia: case report
}

\author{
Jitendra D. Mane* \\ Department of Obstetrics and Gynecology, Military Hospital, Dehradun, Uttarakhand, India \\ Received: 23 July 2017 \\ Revised: 15 August 2017 \\ Accepted: 22 August 2017 \\ *Correspondence: \\ Dr. Jitendra D. Mane, \\ E-mail: jitendra.mane@yahoo.com \\ Copyright: ( $\odot$ the author(s), publisher and licensee Medip Academy. This is an open-access article distributed under \\ the terms of the Creative Commons Attribution Non-Commercial License, which permits unrestricted non-commercial \\ use, distribution, and reproduction in any medium, provided the original work is properly cited.
}

\section{ABSTRACT}

Acute urinary retention is condition which requires immediate attention as it is associated with severe pain and which is relieved by simple procedure of catheterization. This complication is uncommon in women compare to males. It is much rarer during pregnancy. Presenting a case of acute retention of urine in a primigravida woman with vulval edema having severe pre-eclampsia in third trimester. She was initially managed with indwelling Foleys catheter followed by delivery which relieved her symptoms.

Keywords: Retention of urine, Vulval edema, Pre-eclampsia

\section{INTRODUCTION}

Acute urinary retention is defined as the inability to void urine, with a retained volume of urine of $200 \mathrm{ml}$ or greater. ${ }^{1}$ Urinary retention in pregnancy is a relatively uncommon condition. Its relatively low incidence and little published evidence base leads to inconsistent and often suboptimal management.

Acute retention of urine in pregnancy is an emergency which needs prompt diagnosis and treatment if not done may result in irreversible uterine ischemia and spontaneous abortion, rupture of the uterus or bladder, rectal gangrene, intrauterine infection, or death. ${ }^{2}$

Though uncommon during pregnancy but cases are encountered during first and second trimester of pregnancy. Causes of urinary retention are varied like retroverted uterus, pelvic masses, leiomyomas, but here presenting a case of retention of urine during pregnancy following vulval edema in severe pre-eclampsia.

\section{CASE REPORT}

A 20-year-old primigravida was referred from primary health centre at 35 weeks 01 days gestation, with abdominal pain since 3 days and inability of passing urine since 01 day. The pain was in hypogastrium, initially dull then gradually worsened with associated urinary retention. There was no history of fever, trauma, bleeding or leaking per vaginam. She had no problem with her bowel habit but she gave a history of passing small amount of urine frequently over the last few hours. There was no history of allergies in the past. No premonitory symptoms and had not suffered with similar complaints in past. Her medical history was not significant. She had not undergone any surgery in past.

On general examination, her blood pressure was $150 / 100 \mathrm{mmHg}$ with pallor and pedal edema, but she was in distress due to abdominal pain. and severe backache. The uterus was 34-36 weeks gravid uterine size with suprapubic distension of 18-20 weeks size of bladder and 
tender to touch. There was gross edema of her vulva with no local signs of trauma or infection Figure 1.

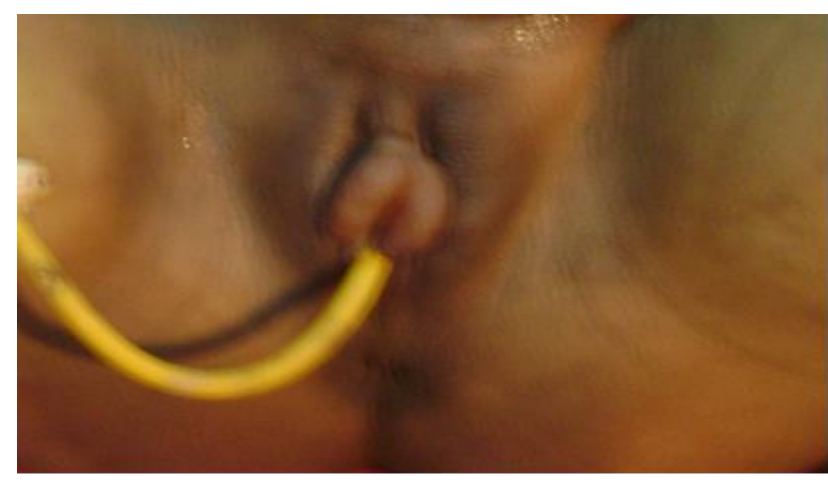

Figure 1: Vulval edema.

On speculum examination, her cervix and vagina were healthy; there was no tenderness in the paraurethral area and the internal examination revealed cervix firm, posterior Os closed. Bladder catheterization drained 1.6 liter of clear urine, after which the suprapubic distension subsided relieving the pain.

Routine antenatal investigations were normal except urine microscopy which revealed 2-3 pus cells, RBC nil and albumin of $2+$. Urine culture had no growth. Hematological and biochemical parameters were normal. Ultrasound scan revealed a normally positioned uterus, with a single fetus of 33 weeks and 02 days gestation with normal placed placenta and liquor volume.

Further there was no evidence of pelvic mass or any bladder, kidneys anatomical lesion. MRI scan could not be done due to non-availability. Initial management done with empirical parentral antibiotics to cover UTI if any and catheter in situ. Catheter was removed after 03 days and still she could not pass urine for $08 \mathrm{hrs}$, hence recatheterization was done. She had preterm delivery at 36weeks following induction for preeclampsia with magnesium sulphate to prevent eclampsia. Catheter was removed after $24 \mathrm{hrs}$ of delivery following which she could micturate freely. Vulval edema subsided after 48 hrs of delivery Figure 2.

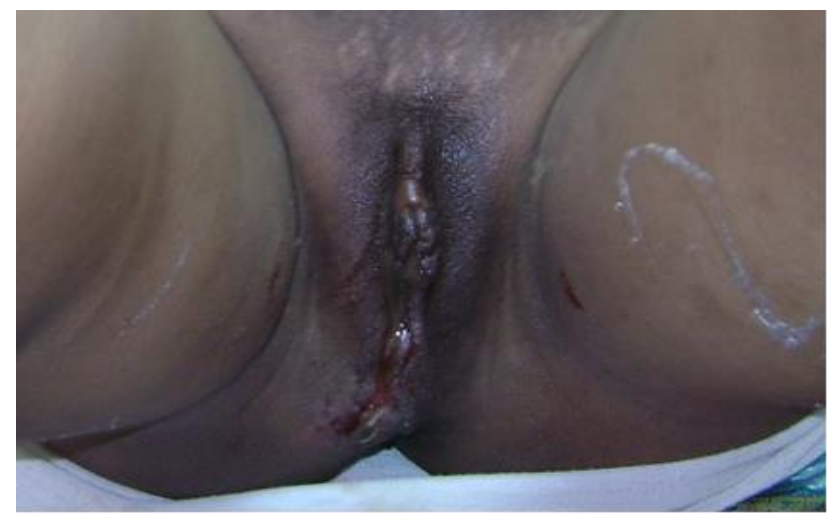

Figure 2: Resolved vulval edema.

\section{DISCUSSION}

Female acute urinary retention is relatively uncommon compared to acute urinary retention in men. Its incidence is reported to be three to seven per 100,000 persons per year. ${ }^{3,4}$ Acute urinary retention during pregnancy is even rare. Etiologies of retention of urine are retroversion of the uterus, a history of pelvic inflammatory disease, and pelvic masses like malignancies, large fibroids. Few cases of ectopic cervical pregnancy leading to urinary retention are reported. Severe vulval edema is a rare complication which can lead to urinary retention. It has been reported in relationship with pre-eclampsia, tocolysis, diabetes with pregnancy and ovarian hyperstimulation in limited numbers. ${ }^{5,6}$ Trauma, infection, vascular or lymphatic obstruction may also cause vulval oedema. Idiopathic vulval odema can be labeled after excluding other causes. ${ }^{7}$ The presence of vulval edema in women with preeclampsia should be considered high risk and require hospitalization for fetal and maternal monitoring. The pathology behind this sign is mainly due to increased vascular permeability and hypoalbuminemia. The treating physician must be prepared for immediate delivery and possible preeclampsia complications in these patients. Mechanical drainage is done to reduce the edema in non-responsive cases. ${ }^{8}$ Clean intermittent catheterisation is a temporizing measure to relieve retention. Ladies with continuous urinary retention despite initial treatment may need chronic therapy. This may be either in the form of clean intermittent catheterisation or by placing a Foley catheter into the bladder either via the urethra or suprapubically which was followed in this case. There is no role for alpha-blockers, or urethral dilatation. The ultimate management in patient having vulval edema secondary to per-eclampsia is to deliver if fetal maturity is achieved so that vulval edema resolves following reversal of preeclampsia pathology.

\section{CONCLUSION}

Vulval edema may be present in cases of pre-eclampsia but vulval edema leading to urinary retention is a rear presentation. Treating the underline cause relives the symptoms in long term and immediately draining the urine using catheter relives symptoms in short term. The aim of presenting this case is to bring out the rarity of the case and to share the experience with others.

\section{Funding: No funding sources Conflict of interest: None declared Ethical approval: Not required}

\section{REFERENCES}

1. Ramsey S, Palmer M. Int Urol Nephrol. 2006; 38:533-5

2. Nelson MS. Acute urinary retention secondary to an incarcerated gravid uterus. Am J Emerg Med. 1986; $4: 231$ 
3. Klarskov P, Andersen JT, Asmussen CF. Acute urinary retention in women: a prospective study of 18 consecutive cases. Scand J Urol Nephrol. 1987;21(1):29-31.

4. Choong S, Emberton M. Acute urinary retention. BJU Int. 2000;85:186-201.

5. Daponte A, Skentou H, Dimopoulos KD, Kallitsaris A. Massive vulvar edema in a woman with preeclampsia: a case report. J Reprod Med. 2007; 52(11):1067-9.

6. Bracero LA, Didomenico A. Massive vulvar edema complicating preeclampsia: a management dilemma J Perinatol. 1991;11(2):122-5.
7. Deren O, Bildirici I, Al A. Massive vulvar oedema complicating a diabetic pregnancy. European Journal of Obstetrics, Gynecol Reproduct Biol. 2000; 93:209-11.

8. Yellamareddygari S.and Ahluwalia A. Acute vulval oedema with urinary retention in pregnancy, J Obstetr Gynaecol. 2006;26:816.

Cite this article as: Mane JD. Acute vulval edema leading to urinary retention in a lady with preeclampsia: case report. Int J Reprod Contracept Obstet Gynecol 2017;6:4718-20. 